\title{
Prevalence and co-occurrence of parentally reported possible asthma and allergic manifestations in pre-school children
}

\author{
Kristina Bröms ${ }^{1,2^{*}}$, Dan Norbäck ${ }^{3}$, Margaretha Eriksson ${ }^{1}$, Claes Sundelin ${ }^{4}$ and Kurt Svärdsudd ${ }^{1}$
}

\begin{abstract}
Background: The aim of this study was to make an in-depth analysis of the prevalence and co-occurrence in preschool children of possible asthma and atopic manifestations.

Methods: In Sweden 74\%-84\% of preschool children, depending on age, attend municipality organised day-care centres. Parents of 5,886 children 1-6 years of age, sampled from day-care centres in 62 municipalities all over Sweden, responded to a postal questionnaire regarding symptoms indicating prevalent possible asthma, allergic rhinitis, eczema, and food, furred pet and pollen allergy and other data in their children. Possible asthma was defined as any of the four criteria wheezing four times or more during the last year, physician diagnosis and current wheezing, ever had asthma and current wheezing, and current use of inhalation steroids, all based on questionnaire responses.
\end{abstract}

Results: The overall prevalence of possible asthma was $8.9 \%$, of eczema $21.7 \%$, of rhinitis $8.1 \%$, and of food allergy $6.6 \%$. There was a highly significant co-occurrence between possible asthma and all atopic manifestations, $35.7 \%$ having any of the manifestations. Presence of pet allergy was the manifestation showing the closest co-occurrence with presence of possible asthma, presence of pollen allergy with presence of rhinitis, and presence of food allergy with presence of eczema. Assessed from plots of age-specific prevalence of possible asthma, rhinitis, eczema and food allergy, the prevalence of all manifestations increased from one to three years of age and then decreased, except for rhinitis where the prevalence increased until six years of age, indicating no specific ordered sequence.

Conclusions: Parentally reported possible asthma, eczema and food allergy had a curvilinear prevalence course across age with a maximum at age 3, while rhinitis prevalence increased consistently with age. Co-occurrence between possible asthma and atopic manifestations was common, and some combinations were more common than others, but there was no evidence of a specific ordered onset sequence.

\section{Background}

In recent decades, the prevalence of allergies and asthma in industrialized countries has increased, particularly among children, although the increase rate may have levelled off during the last few years [1,2]. According to the International Study of Asthma and Allergies in Childhood (ISAAC), the prevalence of asthma and rhino-conjunctivitis among 6- to 7-year-old children in

\footnotetext{
*Correspondence: kristina.broms@pubcare.uu.se

${ }^{1}$ Department of Public Health and Caring Sciences, Family Medicine and

Preventive Medicine, Uppsala University, Uppsala, Sweden

${ }^{2}$ Centre for Clinical Research Uppsala University/County Council of

Gävleborg, Gävle, Sweden

Full list of author information is available at the end of the article
}

Sweden in 2002 was in the middle of the international range, whereas the prevalence of eczema was the highest of all countries participating $[1,3]$. Food allergy prevalence has been less investigated, and the ranking of nations is therefore less certain [4-6].

There are few published studies on age-specific prevalence of asthma, allergic rhinitis henceforth called rhinitis, eczema, and food allergy $[7,8]$. Most studies have been based on certain age groups, for instance 4-year olds, or 6- to 7-year olds, etc., which makes comparisons between studies difficult $[3,9]$. It is well known that that there is co-occurrence between asthma and various atopic manifestations. However, the information on the extent of co-occurrence is still fragmentary [9-11].

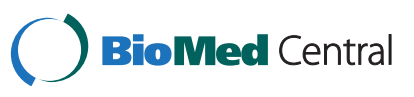

(c) 2013 Bröms et al.; licensee BioMed Central Ltd. This is an Open Access article distributed under the terms of the Creative Commons Attribution License (http://creativecommons.org/licenses/by/2.0), which permits unrestricted use, distribution, and reproduction in any medium, provided the original work is properly cited. 
What is known as the 'atopic march' hypothesis [12-14] is closely linked to this co-occurrence. According to the hypothesis, the onset of atopic manifestations tends to come in an ordered sequence, for instance eczema tends to be followed by asthma. The ideal design to test the hypothesis would be a large, longitudinal cohort study with frequent re-examinations. However, the hypothesis could also, at least provisionally, be tested with a crosssectional study design, given that the onset of the various atopic manifestations always follows the same pattern.

Most Swedish pre-school children attend a day-care centre (DC) [15]. Such centres may therefore be suitable sampling frames for studies of these age groups. The aim of this cross-sectional study was to make an in-depth analysis of the co-occurrence in pre-school children of possible asthma, allergic rhinitis, eczema, and food allergy.

\section{Methods}

\section{Setting}

Sweden is one of the most sparsely populated countries in Europe, the median population density being 26 people per square kilometre, and $80 \%$ of municipalities have 82 people or fewer per square kilometre [16]. The corresponding numbers for the municipalities included in this study were 57 and 130 people. For administrative purposes, Sweden at the time of the data collection was divided into 25 regions and 290 municipalities, the smallest administrative unit.

All Swedish pre-school children are entitled by law to day-care (DC) organised by the local municipality. In 2002, $74 \%$ of all pre-school children attended DC, somewhat fewer among the youngest children and more than $80 \%$ of children of 3 or older [15]. The vast majority of DCs are run by the local municipal administration. The few privately operated DCs are all subcontracted to the municipal administration and follow the same set of rules as publicly operated DCs. A DC may have one to four sections. At the time of the study 15-20 children were cared for in each section. Many sections had children of all ages, but some were age stratified (1-3 years or 4-6 years). The day-care fees are heavily subsidised by the municipalities, parents usually paying about $10 \%$ of the real cost. A detailed description of choice of day care has been given elsewhere [17].

During the 1990s special DCs for children with asthma or allergies, 'allergen avoidance day-care centres' (AADCs) were established at the initiative of municipal school administrations, parents, local politicians, and local DC staffs. The operations, set of rules, and fees are the same as for ordinary day-care centres (ODC) with the exception that AADCs give priority to children with asthma or allergies, but accept other children as well, space permitting. As shown in a previous report all AADCs had strict regulations to avoid pet, smoking, perfume, and dust exposure [18]. The ODCs usually had no such regulations.

\section{Study population}

In the late 1990s all 72 AADCs in Sweden were identified as previously described in detail [18]. The two geographically closest ODCs to each AADC were chosen as control centres. Later, a few AADCs were closed and a few new ones were opened, leaving 70 AADCs with 84 sections and 140 ODCs with 440 sections for this study, in 62 municipalities, all over Sweden. One third of the AADCs were located in the same building as a control ODC. The indoor and outdoor environments at these day-care centres have been reported elsewhere [18].

The addresses of the 1,412 children attending the AADCs and the 7,345 children attending the ODCs were obtained from the local school authorities. A questionnaire was mailed to the parents of these children. Responses were obtained regarding 1,001 AADC children (70.9\%) and 4,958 ODC children (67.5\%), after two reminders when necessary. Of the respondents, 1,000 AADC children and 4,886 ODC children were 6 years old or younger. The ODC children constitute the study population for this report, except in the prevalence calculations, where also data from the AADC children was used.

\section{Questionnaire}

The ISAAC written screening questionnaire with questions about asthma and wheezing, eczema, and rhinitis, extensively used all over the world and regarded as the gold standard for postal questionnaires on childhood asthma, rhinitis, and eczema, was used [1]. Although intended for children 6 years or older, it has been validated down to 3 years old with good results [19]. For this study, supplementary questions on medical treatment, physician assessed asthma, rhinitis and eczema diagnosis, food allergy, allergy to pollen or furred pets, parental education, smoking habits, and some additional variables not reported here, were added (see Additional file 1).

Regarding possible asthma, the following criteria were used: 1) ever had asthma and has current symptoms (wheezing in the last 12 months), or 2) wheezing 4 times or more during the last 12 months, or 3) physician diagnosis and current symptoms, or 4) current use of inhalation steroids. Regarding rhinitis, the following criteria were used: 1) ever had hay-fever and has current symptoms (sneezing or a runny or a blocked nose when the child did not have a cold or the flu), or 2) rhino-conjunctivitis without cold last 12 months, or 3) physician diagnosis and current symptoms, or 4) being on anti-allergy medication and having current symptoms.

The following eczema criteria were used: 1) itchy rash coming and going for at least 6 months in typical eczema localisations in the last 12 months, or 2) physician diagno- 
sis and current symptoms (itchy rash), or 3) current use of steroid ointments and current symptoms. The following food allergy criterion was used: Reported food allergy to milk, egg, fish, peanuts, nuts, soy, or stone fruits, but not including lactose or gluten intolerance.

Parental education was classified as a nine-year compulsory education $(=1)$, a two-year upper secondary education $(=2)$, a three-four-year upper secondary education $(=3)$, or university or other tertiary education $(=4)$.

The study was approved on several occasions before and during the data collection process, first by the Research Ethics Committee at Uppsala University and later by the National Research Ethics Board.

\section{Statistical analysis}

The statistical analyses were conducted using the SAS software, version 9.3 [20]. Partial non-response (missing data in returned questionnaires) was on average $0.6 \%$ with a maximum for individual variables of $1.1 \%$. Simple (crude) differences between groups in proportions were tested with the Mantel-Haenszel chi-square test.

A possible asthma variable $(0=$ no, $1=$ yes $)$ was created based on fulfilment of any of the criteria presented above. A rhinitis, eczema, food allergy, furred pet and pollen allergy variable was constructed accordingly. The variables selected were those of primary interest for the hypothesis. The analyses of co-occurrence between possible asthma, rhinitis, eczema, food, furred pet and pollen allergies were performed with multiple logistic regression analysis with presence of possible asthma, rhinitis and eczema (yes/no) as dependent variables, one at a time, and the others as independent variables, first by age (Figure 1) and then adjusted for the influence of age and sex (Table 1). The analytical technique provides odds ratios (OR), confidence intervals (95\% CI), and Wald's chisquare. The latter is the test variable on which the p-value is based. Consequently, Wald's chi-square may be used to rank the impact of the independent variables on outcome.

Most of the municipalities represented in this study had only one AADC and two ODCs sampled, irrespective of population size, resulting in under-representation of large municipalities in the prevalence calculations. To adjust for this circumstance, an analytical model was employed in which the total number of children, by age and sex, in each municipality represented in the study was downloaded from Statistics Sweden [21]. The number of children with possible asthma, rhinitis, eczema and food allergy by age and sex in the municipality was then computed, based on the prevalence of these conditions in the municipality-specific ODC study populations, after which the number with these diseases in the municipalityspecific AADC study population was added. National prevalence was obtained by pooling the municipalityspecific data on number of cases in relation to exposed population size. The procedure has been described in detail elsewhere [17].

Age was used as a continuous variable and defined as age attained at last birthday. The age-specific prevalence functions were computed with logistic regression technique. The fit between the crude age-specific prevalence and prevalence data generated from the analysis model was tested with a logistic regression technique. To check for non-linearity a model including a second and a third degree age polynomial, and interaction between sex and age were tested. The best fit between observed and expected outcome was obtained with a second degree (possible asthma and rhinitis) or a third degree (eczema and food allergy) age polynomial and an interaction term between sex and age, explaining $50 \%$ of the prevalence variation. On scrutiny, the model fit appeared excellent. All tests were two-tailed. The level of significance was set at $\mathrm{p}<0.05$.

\section{Results}

\section{Characteristics of the study population}

Of the 4,886 ODC children, 2,476 (51\%) were boys. The number of 1-year-old children was 203 (4\%), 2-year-olds 916 (19\%), 3-year-olds 976 (20\%), 4-year-olds 1,017 (21\%), 5-year-olds 1,168 (24\%), and 6-year-olds 606 (12\%). The age distribution was similar in the AADC children. Regarding parental education, 268 (5\%) children had parents with compulsory education only, 1,032 (21\%) had at least one parent with two-year upper secondary education, $1,459(30 \%)$ had at least one parent with three- or fouryear upper secondary education, and 2,127 (44\%) had at least one parent with college or university education.

\section{Possible asthma, rhinitis, eczema, and food, furred pet, and pollen allergy}

Possible asthma, rhinitis and eczema manifestations are presented by age groups in Table 2. The prevalence of possible asthma manifestations was stable or decreased by age, while the prevalence of rhinitis manifestations was stable or increased, and the prevalence of eczema manifestations was generally stable, except that ointment treatment became less prevalent by age.

The prevalence of food, furred pet and pollen allergies is shown in Table 3. The prevalence of egg allergy decreased by age, while the prevalence of peanut and nut allergy increased. All other food allergies had a stable prevalence. The prevalence of all allergies to furred pets increase by age and so did the pollen allergy prevalence.

\section{Age specific prevalence}

The age-specific prevalence of possible asthma, rhinitis, eczema and food allergy adjusted for sampling municipality size is presented in Figure 2. The mean prevalence across age was $21.7 \%$ for eczema, $8.9 \%$ for possible asthma, $8.1 \%$ 

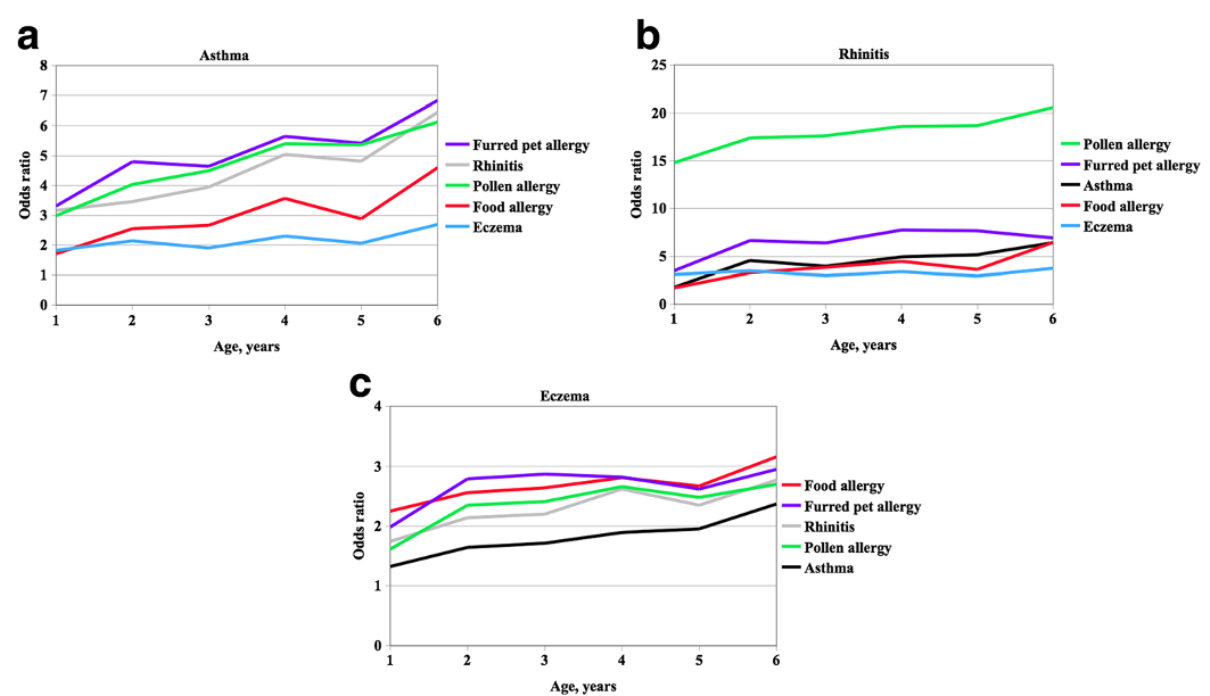

Figure 1 Odds ratio of co-occurrence. Odds ratios by age for co-occurrence of possible asthma versus furred pet allergy, rhinitis, pollen allergy, food allergy and eczema (a), rhinitis versus furred pet allergy, possible asthma, pollen allergy, food allergy and eczema (b), and eczema versus furred pet allergy, rhinitis, pollen allergy, food allergy and possible asthma (c).

for rhinitis, and $6.6 \%$ for food allergy. The prevalence of the most common condition, eczema, increased during the early years of life from $21.3 \%$ at age 1 to $24.1 \%$ at age 3 and then decreased to $18.2 \%$ at age 6 . The possible asthma prevalence increased from $9.3 \%$ at age 1 to $10.6 \%$ at age 3 and then decreased to $5.7 \%$ at age 6 . The rhinitis prevalence increased from $5.2 \%$ at age 1 to $9.9 \%$ at age 6. Food allergy prevalence increased from $3.2 \%$ at age 1 to $8.4 \%$ at age 3 , and was then fairly stable.

\section{Co-occurrence of possible asthma, rhinitis, eczema and allergies}

Crude co-occurrence among the ODC children is illustrated in the Venn diagram in Figure 3, showing that 35.7\% had any of the manifestations. The most common manifestations or manifestation combinations were eczema only, possible asthma, rhinitis, food allergy, and various combinations of eczema, possible asthma and rhinitis, and food allergy.

Statistical measures of co-occurrence between prevalent possible asthma, rhinitis, eczema, and allergies to food, furred pets and pollen in multiple logistic regression analyses are displayed by age in Figure 1a-c and summarised across age in Table 1. Presence of possible asthma (dependent variable) was highly significantly related to the presence of rhinitis, eczema and all the allergy variables (independent variables), after adjustment for the influence on possible asthma prevalence of age and sex (co-variates), indicating a relationship between the presence of possible asthma and presence of all the other variables. The variables with the largest impact on possible asthma prevalence, as indicated by Wald's chi-square, were in ranked order furred pet allergy, rhinitis, food allergy, eczema and pollen allergy. As shown in Figure 1a the co-occurrence between possible asthma on the one hand and rhinitis, furred pet, pollen and food allergy tended to increase by age, while possible asthma-eczema co-occurrence appeared to be more stable across age.

A corresponding analysis (Table 1, mid-section) showed that presence of possible asthma, eczema, food, and pollen allergy were all highly significantly related to presence of rhinitis. Pollen allergy was the far most important determinant, with a Wald's chi-square value more than four times that of all other variables combined. All cooccurrence by age tended to increase except for eczema, Figure 1b.

For eczema presence (Table 1, right hand section), the most important determinant was food allergy, Wald's chi-square measure being larger than that of all other variables combined. The co-occurrence increased by age for all variables, with the largest increase at age 2 and age 6, Figure 1c.

\section{Discussion}

In this nationwide study there was considerable cooccurrence between prevalent possible asthma, rhinitis, eczema and food allergy. The prevalence of all conditions peaked at the age of 3 with the exception of rhinitis, where the prevalence increased throughout the whole age span $1-6$. Eczema was by far the most common of the conditions. The mean prevalence across age of the other manifestations was approximately the same.

The strengths of the study include that it was based on a large sample of pre-school children covering all of Sweden. As shown in the Settings section, $74 \%$ of all 
Table 1 Co-occurrence

\begin{tabular}{|c|c|c|c|c|c|c|c|c|c|c|c|c|}
\hline & & Poss & ble asthma & & & & initis & & & & Eczema & \\
\hline & OR & $95 \% \mathrm{Cl}$ & Wald's chi2 & $p$ & OR & $95 \% \mathrm{Cl}$ & Wald's chi2 & p & OR & $95 \% \mathrm{Cl}$ & Wald's chi2 & $\mathbf{p}$ \\
\hline Age & 0.86 & $0.80-0.92$ & 16.3 & $<0.0001$ & 0.97 & $0.88-1.06$ & 0.5 & 0.49 & 1.0 & $0.95-1.05$ & 0.04 & 0.85 \\
\hline Sex & 1.43 & $1.16-1.77$ & 11.2 & $<0.001$ & 1.02 & $0.78-1.33$ & 0.01 & 0.90 & 0.82 & $0.71-0.95$ & 7.5 & $<0.01$ \\
\hline Possible asthma & $\ldots$ & - & - & - & 2.68 & $1.90-3.79$ & 31.4 & $<0.0001$ & 1.47 & $1.17-1.86$ & 10.5 & $<0.005$ \\
\hline Rhinitis & 2.71 & $1.93-3.81$ & 33.2 & $<0.0001$ & - & - & - & - & 1.94 & $1.46-2.58$ & 20.5 & $<0.0001$ \\
\hline Eczema & 1.48 & $1.17-1.87$ & 10.9 & $<0.001$ & 1.99 & $1.49-2.65$ & 22.1 & $<0.0001$ & - & - & - & - \\
\hline Food allergy & 1.76 & $1.29-2.41$ & 12.6 & $<0.0005$ & 2.07 & $1.41-3.05$ & 13.6 & $<0.0005$ & 3.44 & $2.72-4.34$ & 107.8 & $<0.0001$ \\
\hline Pet allergy & 3.22 & $2.22-4.66$ & 38.4 & $<0.0001$ & 1.55 & $0.96-2.48$ & 3.3 & 0.07 & 2.28 & $1.63-3.19$ & 23.4 & $<0.0001$ \\
\hline Pollen allergy & 1.92 & $1.29-2.85$ & 10.4 & $<0.005$ & 35.39 & $25.23-49.64$ & 426.5 & $<0.0001$ & 1.59 & $1.12-2.23$ & 6.9 & $<0.01$ \\
\hline
\end{tabular}

Effects on the prevalence of current possible asthma, rhinitis, and eczema in logistic regression analyses based on questionnaire data among boys and girls 1-6 years old, attending ordinary day-care centres.

Swedish preschool children, and more than $80 \%$ of children 3 years or older attend day-care centres. Children in Swedish day care centres may thereby be regarded as representative of all Swedish preschool children. One possible source of bias might have been that children attending DCs were more or less healthy than nonattending children. However, some studies have found that children attending DCs had more respiratory symptoms than children cared for at home [22], while others found no difference [23], and still others have found differences only in specific age groups [24]. At any rate the differences found were small.

Moreover, the parental response rate to the postal questionnaire was $68-71 \%$, which is higher than the approximately 50\%- 60\% response rate usually obtained in random population samples. The data obtained in this study are therefore equal to or more complete than corresponding data obtained from random population samples. The possible bias caused by non-response may be estimated based on the assumptions that non-respondents,

\section{Table 2 Manifestation prevalence}

\begin{tabular}{|c|c|c|c|c|}
\hline & \multicolumn{3}{|c|}{ Age groups, years } & \multirow[b]{2}{*}{$\mathbf{p}$} \\
\hline & $1-2$ & 3-4 & $5-6$ & \\
\hline$n$ & 1119 & 1993 & 1774 & \\
\hline \multicolumn{5}{|l|}{ Asthma manifestations, n (\%) } \\
\hline Ever had asthma and current ${ }^{*}$ symptoms & $81(7.3)$ & $153(7.7)$ & $94(5.3)$ & $<0.05$ \\
\hline Wheezing 4 times or more last 12 months & $77(6.9)$ & $94(4.7)$ & $64(3.6)$ & $<0.0001$ \\
\hline Physician diagnosis and current ${ }^{*}$ symptoms & $69(6.2)$ & $142(7.2)$ & $88(5.1)$ & 0.10 \\
\hline Being on inhalation steroids & $57(5.1)$ & $129(6.7)$ & $88(5.0)$ & 0.64 \\
\hline Any asthma criterion & $114(10.2$ & $195(9.8)$ & $132(7.4)$ & $<0.01$ \\
\hline \multicolumn{5}{|l|}{ Rhinitis manifestations $\mathrm{n}(\%)$} \\
\hline Ever had hay-fever and current ${ }^{*}$ symptoms & $43(3.8)$ & $86(4.3)$ & $105(5.9)$ & $<0.01$ \\
\hline Rhino-conjunctivitis without cold last 12 months & $49(4.4)$ & $97(4.9)$ & $94(5.3)$ & 0.26 \\
\hline Physician rhinitis diagnosis and current ${ }^{*}$ symptoms & $10(0.9)$ & $35(1.8)$ & $58(3.3)$ & $<0.0001$ \\
\hline On anti-allergy medication and current ${ }^{*}$ symptoms & $17(1.5)$ & $41(2.1)$ & $66(3.7)$ & $<0.0001$ \\
\hline Any rhinitis criterion & $79(7.1)$ & $137(6.9)$ & $145(8.2)$ & 0.20 \\
\hline \multicolumn{5}{|l|}{ Eczema manifestations, n (\%) } \\
\hline $\begin{array}{l}\text { Itchy rash ever, coming and going for } \geq 6 \text { months, and itchy rash in } \\
\text { typical eczema localisations last } 12 \text { months }\end{array}$ & $224(20.4)$ & $416(21.0)$ & $383(21.8)$ & 0.31 \\
\hline Physician eczema diagnosis and current $\left.{ }^{*}\right)$ symptoms & $102(9.2)$ & $198(10.0)$ & $183(10.4)$ & 0.31 \\
\hline Steroid ointments last 12 months and current ${ }^{*}$ symptoms & $98(8.8)$ & $141(7.1)$ & $117(6.6)$ & $<0.05$ \\
\hline Any eczema criterion & $240(21.5)$ & $444(22.3)$ & $398(22.4)$ & 0.56 \\
\hline
\end{tabular}

Prevalence $n$ (\%) of current possible asthma, rhinitis and eczema manifestations based on questionnaire data in boys and girls 1-6 years old attending ordinary day-care centres.

${ }^{*}$ Current indicates symptoms of the specific disease at any time during the last 12 months. 
Table 3 Allergy prevalence

\begin{tabular}{lccccc}
\hline & \multicolumn{4}{c}{ Age groups, years } & \\
\cline { 2 - 3 } & $\mathbf{1 - 2}$ & $\mathbf{3 - 4}$ & $\mathbf{5 - 6}$ & $\mathbf{p}$ \\
\hline Reported food allergy & $38(3.4)$ & $88(4.4)$ & $75(4.3)$ & 0.34 \\
Milk allergy & $37(3.3)$ & $48(2.4)$ & $33(1.9)$ & $<0.05$ \\
Egg allergy & $11(1.0)$ & $15(0.8)$ & $19(1.1)$ & 0.70 \\
Fish allergy & $13(1.2)$ & $37(1.9)$ & $42(2.4)$ & $<0.05$ \\
Peanut allergy & $14(1.3)$ & $28(1.4)$ & $41(2.3)$ & $<0.05$ \\
Nut allergy & $6(0.5)$ & $16(0.8)$ & $8(0.5)$ & 0.63 \\
Soy allergy & $9(0.8)$ & $20(1.0)$ & $24(1.4)$ & 0.15 \\
Stone fruit allergy & $78(7.0)$ & $150(7.5)$ & $140(7.9)$ & 0.34 \\
Any food allergy & & & & \\
Allergy to furred pets & $21(1.9)$ & $55(2.8)$ & $77(4.4)$ & $<0.0001$ \\
Cat allergy & $9(0.8)$ & $45(2.3)$ & $57(3.2)$ & $<0.0001$ \\
Dog allergy & 0 & $19(1.0)$ & $34(1.9)$ & $<0.0001$ \\
Horse allergy & $4(0.4)$ & $24(1.2)$ & $41(2.3)$ & $<0.0001$ \\
Rodent allergy & $25(2.3)$ & $79(4.0)$ & $103(5.9)$ & $<0.0001$ \\
Any allergy to furred pets & $42(3.8)$ & $94(4.8)$ & $124(7.1)$ & $<0.0001$ \\
\hline Pollen allergy & & & & \\
\hline
\end{tabular}

Prevalence of current food, furred pet and pollen allergy based on questionnaire data in boys and girls 1-6 years old attending ordinary day-care centres.

for instance, had a possible asthma on average either five standard error units more often or five standard error units less often then the respondents, i.e., a considerable and highly significant difference. The overall possible asthma prevalence in respondents and non-respondents combined would then have been $9.0 \%$ if non-respondents had higher prevalence than respondents, and $8.8 \%$ if they had lower prevalence, as compared with the $8.9 \%$ we found among respondents. The potential bias owing to non-response is therefore small.

The limitations of the study include that postal questionnaire data was the only possible source of information in a study population of this size. It would have been desirable to have access to medical investigation data, however impractical with a study population of this size and dispersion across the country. The questionnaire used in this study is based on the ISAAC questionnaire, validated and used worldwide. All sources of information have inherent information bias to some extent. Medical history data usually have a low degree of such bias, and according to the validations made it is acceptable for clinical epidemiologic studies, like the present one.

The definitions of possible asthma and allergic manifestations were based on combinations of variables. Possible asthma, for instance, is in most prevalence studies defined only by wheezing during the last year. In a previous publication we were able to show that the prevalence of possible asthma criteria used in the present study was approximately the same per age and sex group, except for wheezing alone during the last year, where the prevalence was almost three times higher (approximately 35\% among one-year-old boys and 19\% among one-year old girls) [17]. To improve precision and to arrive at a definition as similar as possible to that used in a clinical setting, the criteria used in this study were adopted.

In this study the total prevalence of possible asthma, rhinitis, eczema or food allergy across the age span 16 years was $35.7 \%$. A previous Swedish study found a similar total prevalence, $32 \%$ [9]. The $8.9 \%$ possible asthma prevalence is similar to what others have found $[7,9,25]$. We found a total rhinitis prevalence of $8.1 \%$.

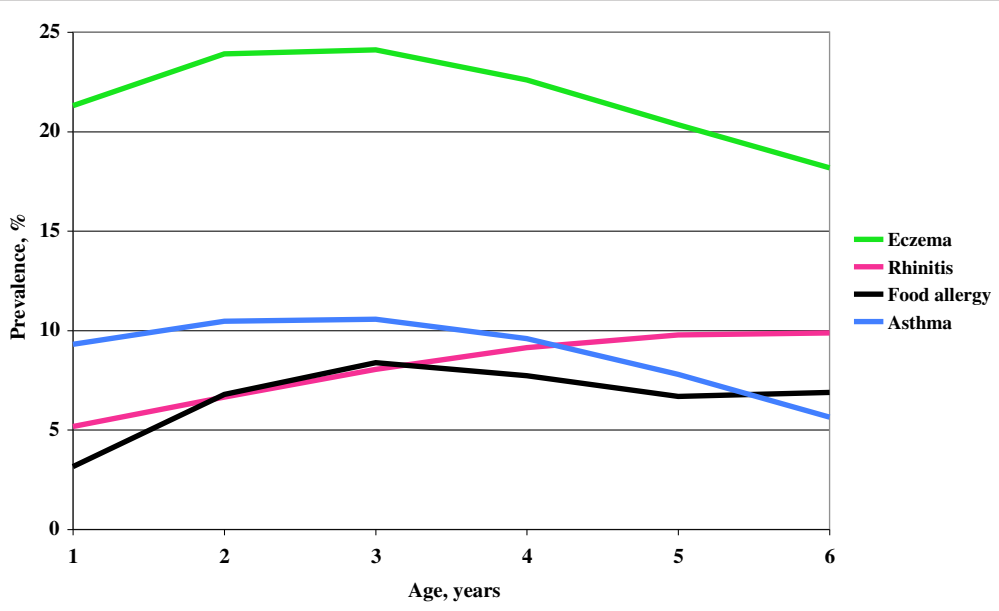

Figure 2 Overlap between parentally reported possible asthma, rhinitis, eczema and food allergy. Age specific prevalence (\%) of possible asthma, rhinitis, eczema, and food allergy among Swedish pre-school children based on application of study questionnaire data to Swedish national data on preschool children. 


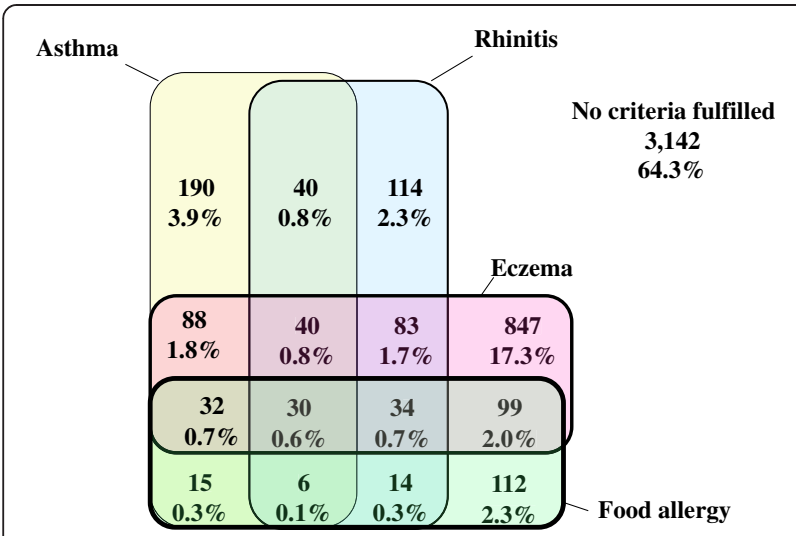

Figure 3 Parentally reported prevalence. Venn diagram showing overlap between presence (\%) of possible asthma, rhinitis, eczema and food allergy in children 1-6 years old attending ordinary daycare centres. Percentages refer to crude number of children with criterion or criteria combinations in relation to total ordinary daycare study population.

Other western and northern European studies have reported similar prevalence levels [3,9]. The eczema prevalence found in this study, $21.7 \%$, is similar to results from other Swedish studies $[3,26]$, but higher than results reported from other European and non-European countries in the ISAAC study [3]. The food allergy prevalence in the present study was $6.6 \%$. Other Scandinavian and British studies reported $8 \%-15 \%$, based on questionnaires $[4,27,28]$, but only $2 \%-3.5 \%$ after oral provocation [5,27-30]. The results from this study are thus similar to those from other Scandinavian studies, but they differ to some extent from data collected in other parts of the world.

We found a highly significant co-occurrence between the various atopic manifestations. Pet allergy and rhinitis had the largest impact effect of the allergy manifestations on the presence of possible asthma. Regarding rhinitis, pollen allergy had by far the largest impact. For eczema, food allergy had the unquestionably largest impact. These findings are well in line with clinical observations. Results from other studies are usually based on two-bytwo manifestation comparisons, with a few exceptions [10-12,30,31] and with only partial adjustments, which means that the extent of the co-occurrence is only partially shown.

There are two interesting issues linked to co-occurrence: cause or causes and consequences. It is unlikely that the various atopic manifestations cause or trigger each other, it is much more likely that there are common underlying factors that trigger the onset of manifestations. These are presently incompletely known. It is a commonly held view that the manifestations become prevalent in some sort of ordered sequence, such as the 'atopic march'
[12-14]. So far, no preventive action may be based on these circumstances.

However, in a German birth cohort study, children with moderate to severe early eczema often had early wheeze. Of these children, half had wheeze before the onset of eczema and half had eczema before or concomitant with wheezing [14]. As early as at 2 years of age, 6.5\% of the children in a Swedish birth cohort study had at least three of five atopic manifestations [32]. In the present study co-occurrences were common as early as before 3 years of age. The impact of pollen allergy as compared with that of furred pet allergy on rhinitis was larger than expected in these young children and is particularly noteworthy.

\section{Conclusions}

In conclusion, all but one manifestation had peak prevalence at 3 years of age. Although the present study is based on cross-sectional data, where the manifestations among individual children were not followed over time, there was no indication that the manifestations appeared in rank order. They rather appeared to have their onset at about the same time, possibly with the exception of rhinitis. Cooccurrence between parentally reported possible asthma and the atopic manifestations was common, and some combinations were more common than others.

\section{Consent}

Written informed consent was obtained from the parents for the publication of this report and any accompanying images.

\section{Additional file}

Additional file 1: Supplementary questions.

\section{Competing interests}

The authors declare that they have no competing interests.

\section{Authors' contributions}

All authors participated in the design of the study. KB and KS performed the sampling of the study population. $\mathrm{KB}, \mathrm{ME}$ and $\mathrm{KS}$ performed the monitoring of the data collection and corrected and revised the data files. KB and KS performed the analyses and drafted the manuscript. All authors participated in the discussions and revisions of the manuscript, and all authors have seen and approved the final version.

\section{Acknowledgements}

This study was supported by grants from The Varrdal Foundation for Health Care Sciences and Allergy Research, the Swedish Asthma and Allergy Association, Max Mathiessen Foundation, Bror Hjerpstedt Foundation, CFUG Gävleborg County/Uppsala University, the Gästrikland Primary Health Care Administration, and Uppsala University.

\section{Author details}

${ }^{1}$ Department of Public Health and Caring Sciences, Family Medicine and Preventive Medicine, Uppsala University, Uppsala, Sweden. ${ }^{2}$ Centre for Clinical Research Uppsala University/County Council of Gävleborg, Gävle, Sweden. ${ }^{3}$ Department of Medical Sciences, Occupational and Environmental 
Medicine, Uppsala University, Uppsala, Sweden. ${ }^{4}$ Department of Women's and Children's Health, Paediatrics, Uppsala University Hospital, Uppsala, Sweden.

Received: 13 February 2013 Accepted: 1 August 2013

Published: 16 August 2013

\section{References}

1. Asher Ml, Keil U, Anderson HR, Beasley R, Crane J, Martinez F, Mitchell EA, Pearce N, Sibbald B, Stewart AW, et al: International Study of Asthma and Allergies in Childhood (ISAAC): rationale and methods. Eur Respir J 1995, 8(3):483-491.

2. Grize L, Gassner M, Wuthrich B, Bringolf-Isler B, Takken-Sahli K, Sennhauser FH, Stricker T, Eigenmann PA, Braun-Fahrlander C: Trends in prevalence of asthma, allergic rhinitis and atopic dermatitis in 5-7-year old Swiss children from 1992 to 2001. Allergy 2006, 61(5):556-562.

3. Asher MI, Montefort S, Bjorksten B, Lai CK, Strachan DP, Weiland SK, Williams $\mathrm{H}$ : Worldwide time trends in the prevalence of symptoms of asthma, allergic rhinoconjunctivitis, and eczema in childhood: ISAAC Phases One and Three repeat multicountry cross-sectional surveys. Lancet 2006, 368(9537):733-743.

4. Ostblom E, Lilja G, Pershagen G, van Hage M, Wickman M: Phenotypes of food hypersensitivity and development of allergic diseases during the first 8 years of life. Clin Exp Allergy 2008, 38(8):1325-1332.

5. Rona RJ, Keil T, Summers C, Gislason D, Zuidmeer L, Sodergren E, Sigurdardottir ST, Lindner T, Goldhahn K, Dahlstrom J, et al: The prevalence of food allergy: a meta-analysis. J Allergy Clin Immunol 2007, 120(3):638-646.

6. Steinke M, Fiocchi A, Kirchlechner V, Ballmer-Weber B, Brockow K, Hischenhuber C, Dutta M, Ring J, Urbanek R, Terracciano L, et al: Perceived food allergy in children in 10 European nations. A randomised telephone survey. Int Arch Allergy Immunol 2007, 143(4):290-295.

7. Bornehag CG, Sundell J, Hagerhed-Engman L, Sigsggard T, Janson S, Aberg $\mathrm{N}$ : 'Dampness' at home and its association with airway, nose, and skin symptoms among 10,851 preschool children in Sweden: a crosssectional study. Indoor Air 2005, 15(Suppl 10):48-55.

8. Caudri D, Wijga A, Gehring U, Smit HA, Brunekreef B, Kerkhof M, Hoekstra M, Gerritsen J, de Jongste JC: Respiratory symptoms in the first 7 years of life and birth weight at term: the PIAMA Birth Cohort. Am J Respir Crit Care Med 2007, 175(10):1078-1085.

9. Wickman M, Lilja G, Soderstrom L, van Hage-Hamsten M, Ahlstedt S: Quantitative analysis of IgE antibodies to food and inhalant allergens in 4 -year-old children reflects their likelihood of allergic disease. Allergy 2005, 60(5):650-657.

10. Peroni DG, Piacentini GL, Alfonsi L, Zerman L, Di Blasi P, Visona G, Nottegar F, Boner AL: Rhinitis in pre-school children: prevalence, association with allergic diseases and risk factors. Clin Exp Allergy 2003, 33(10):1349-1354.

11. Ronmark E, Perzanowski M, Platts-Mills T, Lundback B: Different sensitization profile for asthma, rhinitis, and eczema among 7-8-year-old children: report from the Obstructive Lung Disease in Northern Sweden studies. Pediatr Allergy Immunol 2003, 14(2):91-99.

12. Burgess JA, Lowe AJ, Matheson MC, Varigos G, Abramson MJ, Dharmage SC: Does eczema lead to asthma? J Asthma 2009, 46(5):429-436

13. Gustafsson D, Sjoberg O, Foucard T: Development of allergies and asthma in infants and young children with atopic dermatitis-a prospective follow-up to 7 years of age. Allergy 2000, 55(3):240-245.

14. Illi S, von Mutius E, Lau S, Nickel R, Gruber C, Niggemann B, Wahn U: The natural course of atopic dermatitis from birth to age 7 years and the association with asthma. J Allergy Clin Immunol 2004, 113(5):925-931.

15. The Swedish National Agency for Education; 2013. www.skolverket.se. The Swedish National Agency for Education (last accessed on 5 February ,2013).

16. Swedish Association of Local Authorities and Regions; 2013. www.skl.se. Swedish Association of Local Authorities and Regions (in Swedish, Sveriges Kommuner och Landsting) (last accessed on 5 February, 2013).

17. Broms K, Norback D, Eriksson M, Sundelin C, Svardsudd K: Effect of degree of urbanisation on age and sex-specific asthma prevalence in Swedish preschool children. BMC Public Health 2009, 9:303.

18. Broms K, Svardsudd K, Sundelin C, Norback D: A nationwide study of indoor and outdoor environments in allergen avoidance and conventional daycare centers in Sweden. Indoor Air 2006, 16(3):227-235.
19. Mata Fernandez C, Fernandez-Benitez M, Perez Miranda M, Guillen Grima F: Validation of the Spanish version of the Phase III ISAAC questionnaire on asthma. J Investig Allergol Clin Immunol 2005, 15(3):201-210.

20. SAS Institute Inc; 2013. www.sas.com 9.3 edition: Cary, NC: SAS Institute Inc.. (last accessed on 5 February, 2013).

21. Statistics Sweden; 2013. www.ssd.scb.se. Statistics Sweden (last accessed on 5 February, 2013).

22. Koopman LP, Smit HA, Heijnen ML, Wijga A, van Strien RT, Kerkhof M, Gerritsen J, Brunekreef B, de Jongste JC, Neijens HJ: Respiratory infections in infants: interaction of parental allergy, child care, and siblings- The PIAMA study. Pediatrics 2001, 108(4):943-948.

23. Nafstad $P$, Hagen JA, Oie L, Magnus $P$, Jaakkola JJ: Day care centers and respiratory health. Pediatrics 1999, 103(4 Pt 1):753-758.

24. Hagerhed-Engman L, Bornehag CG, Sundell J, Aberg N: Day-care attendance and increased risk for respiratory and allergic symptoms in preschool age. Allergy 2006, 61(4):447-453.

25. Pearce N, Ait-Khaled N, Beasley R, Mallol J, Keil U, Mitchell E, Robertson C: Worldwide trends in the prevalence of asthma symptoms: phase III of the International Study of Asthma and Allergies in Childhood (ISAAC). Thorax 2007, 62(9):758-766.

26. Larsson M, Hagerhed-Engman L, Sigsgaard T, Janson S, Sundell J, Bornehag CG: Incidence rates of asthma, rhinitis and eczema symptoms and influential factors in young children in Sweden. Acta Paediatr 2008, 97(9):1210-1215.

27. Osterballe M, Hansen TK, Mortz CG, Host A, Bindslev-Jensen C: The prevalence of food hypersensitivity in an unselected population of children and adults. Pediatr Allergy Immunol 2005, 16(7):567-573.

28. Venter C, Pereira B, Grundy J, Clayton CB, Arshad SH, Dean T: Prevalence of sensitization reported and objectively assessed food hypersensitivity amongst six-year-old children: a population-based study. Pediatr Allergy Immunol 2006, 17(5):356-363.

29. Eller E, Kjaer HF, Host A, Andersen KE, Bindslev-Jensen C: Food allergy and food sensitization in early childhood: results from the DARC cohort. Allergy 2009, 64(7):1023-1029.

30. Ostblom E, Wickman M, van Hage M, Lilja G: Reported symptoms of food hypersensitivity and sensitization to common foods in 4-year-old children. Acta Paediatr 2008, 97(1):85-90.

31. Hamelmann E, Beyer K, Gruber C, Lau S, Matricardi PM, Nickel R, Niggemann B, Wahn U: Primary prevention of allergy: avoiding risk or providing protection? Clin Exp Allergy 2008, 38(2):233-245.

32. Kull I, Wickman M, Lilja G, Nordvall SL, Pershagen G: Breast feeding and allergic diseases in infants-a prospective birth cohort study. Arch Dis Child 2002, 87(6):478-481.

doi:10.1186/1471-2458-13-764

Cite this article as: Bröms et al.: Prevalence and co-occurrence of parentally reported possible asthma and allergic manifestations in preschool children. BMC Public Health 2013 13:764.

\section{Submit your next manuscript to BioMed Central and take full advantage of:}

- Convenient online submission

- Thorough peer review

- No space constraints or color figure charges

- Immediate publication on acceptance

- Inclusion in PubMed, CAS, Scopus and Google Scholar

- Research which is freely available for redistribution 